\title{
Unconformable stratigraphy in East Antarctica: Part II. Englacial cosets and recrystallized layers
}

\author{
Steven A. ARCONE, ${ }^{1}$ Robert JACOBEL, ${ }^{2}$ Gordon HAMILTON ${ }^{3}$ \\ ${ }^{1}$ US Army Engineer Research and Development Center, Cold Regions Research and Engineering Laboratory, \\ Hanover, NH 03755-1290, USA \\ E-mail: Steven.A.Arcone@usace.army.mil \\ ${ }^{2}$ Department of Physics, St Olaf College, Northfield, MN 55057, USA \\ ${ }^{3}$ Climate Change Institute, University of Maine, Orono, ME 04469, USA
}

\begin{abstract}
Complex unconformable englacial stratigraphy, including a segment of distinctive cosets of bed sequences, occurs throughout the thickness of a $3.2 \mathrm{MHz}$ ice-sheet radar profile we acquired across the upper Byrd Glacier (East Antarctica) catchment. Some cosets span $>10 \mathrm{~km}$, are $>100 \mathrm{~m}$ thick and are delineated by distinct horizons. At 40-90 m depth in firn, comparisons between $200 \mathrm{MHz}$ and specially processed $3.2 \mathrm{MHz}$ profiles reveal that the delineating horizons result from density-modified layers produced by decades to millennia of subaerial exposure, as detailed in our related paper (Part I). These comparisons, together with reflected waveforms at depth, also reveal that the modified layers retain their chemical stratification, and therefore the original unconformable surface. Two profile segments show high-amplitude transverse folds spanning much of the ice-sheet thickness. The parallel nature of most of them suggests basal sliding beneath long-term up-ice-flow accumulation zones, which we identify in satellite images as the likely sources for the cosets. The unconformable stratigraphy at depths greater than $2000 \mathrm{~m}$ shows that antidunal deposition and intense firn recrystallization zones have persisted for tens of thousands of years in this region of East Antarctica.
\end{abstract}

\section{INTRODUCTION}

\subsection{Unconformable stratigraphy}

Unconformities characterize the stratigraphy beneath the large megadune fields of East Antarctica. These fields, covering an estimated $500000 \mathrm{~km}^{2}$, are particularly preva lent in the Byrd Glacier catchment (Fig. 1). They are characterized by low-amplitude trains of dunes having wavelengths of $2-5 \mathrm{~km}$ and amplitudes of 2-8 $\mathrm{m}$ (Fahnestock and others, 2000; Frezzotti and others, 2002). Ground-penetrating radar (GPR) profiles have revealed that regular series of prograded bedding sequences, known as cosets, $7-12 \mathrm{~m}$ thick and up to $10 \mathrm{~km}$ long form in the firn beneath these trains (Fahnestock and others, 2004; Scambos and others, 2004). Along the traverse shown in Figure 1, Arcone and others (2012; hereafter referred to as Part I) showed that similar but more irregular stratigraphy forms within the firn of the peripheral areas, as well, and contains considerably larger cosets. Here we discuss similar englacial features we imaged to $>2 \mathrm{~km}$ deep with GPR along the same traverse, and which allow us to generalize this stratigraphy to much of the catchment.

As discussed in Part I, in the megadunes environment, accumulation is confined to windward slopes, a process known as antidunal accumulation. This results in cosets, which extend beneath the leeward slopes, and then the next windward slope in the downwind direction. The larger and more irregular cosets we discuss in Part I generate at large windward slopes that appear to be controlled by subglacial relief, so they are stable with respect to bed features. Through modeling we find average accumulation rates along windward slopes as high as $0.16 \mathrm{~m}$ w.e. $\mathrm{a}^{-1}$ result from topographic stability, and an unusual ice speed near $30 \mathrm{~m} \mathrm{a}^{-1}$. These rates and speed are much higher than estimated regional values. The accumulating and prograding slopes of these cosets, as well as those of megadunes, correlate closely with dark areas we see in a RADARSAT image of the Byrd catchment. The unconformities result from the accumulation hiatus of the wind-glazed leeward slopes. Recrystallization beginning just beneath the glaze forms layers in which the density stratification of the older coset beds appears modified or eliminated. The layers continue to grow both upward and downward after burial, possibly aided by vapor transport (Severinghaus and others, 2010; Part I).

For $650 \mathrm{~km}$ from site 7-1 (Fig. 1) we recorded englacial stratigraphy to the ice bed using a 3.2 MHz GPR (Jacobel and others, 2008, 2010; Welch and others, 2009). Unconformable horizons appear at depth throughout this segment of the traverse and are typically less than $\sim 30 \mathrm{~km}$ long, which is similar to the coset lengths found in Part I. The in situ pulse length of $80 \mathrm{~m}$ for this radar gives a vertical horizon resolution of $40 \mathrm{~m}$ (Fig. 2). This resolution is comparable with the thickness of the cosets shown in Part I. Although the $40 \mathrm{~m}$ resolution precluded the imaging of thinner coset bedding sequences, along one segment thicker sequences are prominent, some having dimensions that range over $100 \mathrm{~m}$ (Welch and others, 2009). Thinned by compression at depth, these features evolve from much thicker sequences near the surface. Also important to our interpretation is that $3.2 \mathrm{MHz}$ signals respond primarily to contrasts in conductivity, $\sigma$, between acidic layers (Moore and others, 1992; Hempel and others, 2000), whereas $200 \mathrm{MHz}$ (and higher) signals respond primarily to density contrasts (Arcone and others, 2004, 2005a,b; Part I). This poses the question of whether or not the recrystallization that modified our $200 \mathrm{MHz}$ density strata in firn has modified the acidity strata as well. We explore this question below.

\subsection{Objectives and approach}

Here we describe the morphology and dimensions of the deeper englacial cosets and explore how they relate to those 


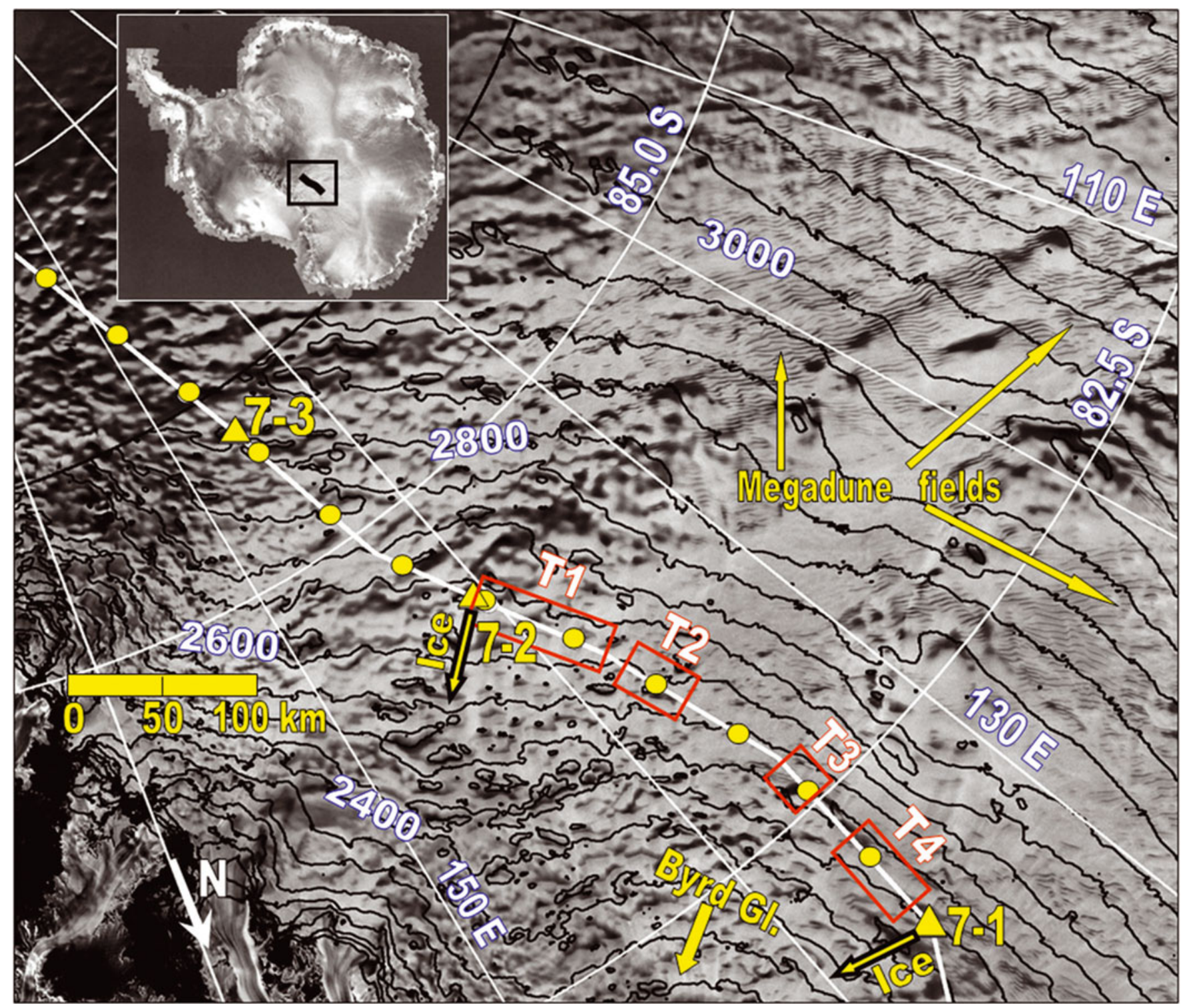

Fig. 1. The 1997 RADARSAT-1 image of part of East Antarctica, with the 2007 US-ITASE II traverse superimposed. Yellow dots along the traverse are $50 \mathrm{~km}$ apart. Elevation contours are in $50 \mathrm{~m}$ increments. The megadune fields appear as dark and light stripes, which indicate windward and leeward slopes, respectively. Peripheral to, and within the fields are sporadic dark-toned areas of accumulation. Unconformable stratigraphy extends $\sim 650 \mathrm{~km}$ south of site 7-1. The boxes indicate segments T1-T4. Yellow triangles mark sites 7-1, 7-2 and 7-3 where we obtained ice velocities and cores.

we profiled in firn. Our main objective is to determine if the modified firn layers are visible in the englacial profile and if so, why. We consider the resolution limitations of our 3.2 $\mathrm{MHz}$ pulse, the waveforms of horizons that appear to delineate the cosets, and compare high- and low-frequency GPR profiles of recrystallized firn to find more evidence of the fate of acidic strata. A second objective is to find if these large and deep cosets are related to present upstream surface features, which would imply their long-term spatial stability, as suggested by our results in Part I. We use previously mapped ice flowlines and the parallel nature of deep stratigraphic folding to argue that these englacial cosets were generated by features identified within RADARSAT imagery.

Linking englacial features from one radar profile to the other within the firn regime is not straightforward because of the minimal region of overlap in the depth dimension. We recorded $200 \mathrm{MHz}$ profiles from the surface to only $90 \mathrm{~m}$ depth, while the coverage at $3.2 \mathrm{MHz}$ typically extends from $135-150 \mathrm{~m}$ to the bed because direct coupling between the $3.2 \mathrm{MHz}$ antennas masked the stratigraphy above. However, at a compromise in vertical resolution we alleviated the direct coupling with a high-pass filter that created a 10$20 \mathrm{MHz}$ bandwidth multi-cycle signal that enabled us to resolve more of the shallow internal stratigraphy. After applying a normal moveout correction to compensate for the wide antenna separation and correct for horizon dip, we image all but the top $42 \mathrm{~m}$. Thus, the $200 \mathrm{MHz}$ and the filtered 3.2 MHz GPR profiles overlap from 42 to $90 \mathrm{~m}$. For the typically weak firn values of $10^{-6}<\sigma<10^{-5} \mathrm{~S} \mathrm{~m}^{-1}$ (Shabtaie and Bentley, 1995), an interfacial Fresnel reflection coefficient is proportional to the contrast, $\Delta \sigma$, between ice layers (Arcone and Kreutz, 2009), and inversely proportional to frequency. This means that a typical acidity contrast will be at least $20 \mathrm{~dB}$ stronger in the filtered low-frequency data than at $200 \mathrm{MHz}$ and therefore will likely be detectable. 


\section{STUDY SITE}

Figure 1 superimposes part of the 2007 United States International Trans-Antarctic Scientific Expedition (US-ITASE; Mayewski, 2003) traverse, which includes the segments that we discuss, upon the 1997 RADARSAT mosaic. This part of the traverse crossed the Byrd Glacier catchment (Stearns, 2007) which extends to $\sim 15 \mathrm{~km}$ south of site $7-2$. The traverse was occasionally near a few megadune features, but at least $130 \mathrm{~km}$ from continuous megadune fields. The englacial stratigraphy in this traverse portion is characterized by unconformities for $650 \mathrm{~km}$ south of site $7-1$. By $750 \mathrm{~km}$ south of 7-1 both firn and englacial horizons become continuous and surface-conformable.

The traverse segments are nearly orthogonal to ice flow, with speeds of $86.71 \mathrm{~m} \mathrm{a}^{-1}(7-1), 30.09 \mathrm{~m} \mathrm{a}^{-1}$ (7-2) and $41.47 \mathrm{ma}^{-1}$ (7-3), measured at an accuracy of about $\pm 5.8 \mathrm{~m} \mathrm{a}^{-1}$. These speeds are qualitatively consistent with the balance velocities of Bamber and others (2009), and the directions are consistent with flowlines (Liu and others, 1999) shown later. The local average surface katabatic wind directions are based on atmospheric modeling (Parish and Bromwich, 1987; Parish, 1988; also shown by Siegert and others, 2003). The wind direction is generally south to north and parallel to our traverse near site $7-2$. By $100-150 \mathrm{~km}$ south of site 7-1 the wind turns towards the Ross Ice Shelf, and at $35^{\circ}$ to the northeast. Ice cores to $40-50 \mathrm{~m}$ depth obtained at these three sites contain extensive recrystallization, so dating them has not been possible.

\section{METHODS}

\subsection{GPR}

We describe the $200 \mathrm{MHz}$ system (Fig. 2a), pulse waveform, and processing we used for profiling of firn in Part I. The 1.5wavelength $200 \mathrm{MHz}$ pulse has a length of $1.4 \mathrm{~m}$ in $\varepsilon=2.7$ firn, which gives a $0.7 \mathrm{~m}$ reflection horizon resolution in the vertical dimension.

We constructed our own deep-sounding system (Welch and Jacobel, 2003, 2005), including resistively loaded dipoles towed collinearly, with each arm $20 \mathrm{~m}$ long (Fig. $3 \mathrm{~b}$ and c). The peak amplitude of the pulse spectrum is $3.2 \mathrm{MHz}$ (Fig. 2), which we determined from a subglacial lake reflection farther along the traverse (Welch and others, 2009). The -+- amplitude polarity sequence of the waveform appears as black-white-black bands in a profile. This particular waveform characterizes a reflection from an interface between a relatively lower permittivity or conductivity material (e.g. ice) above and a relatively higher material (water, rock, sediments, more conductive ice) below, or from a thin (relative to a wavelength) ice layer embedded in a relatively less conductive ice matrix.

The peak radiated power was $\sim 2.5 \mathrm{~kW}$. After analog-todigital conversion of the radio-frequency signals, we recorded 8192 14-bit samples per trace at an interval of $5 \mathrm{~ns}$ to give a total time range of $\sim 43 \times 10^{3} \mathrm{~ns}(3.6 \mathrm{~km}$ in ice). Each trace was recorded after a 1000-fold stack, which provides $30 \mathrm{~dB}$ suppression of random noise. Profile traces are typically recorded every 3-4 $\mathrm{m}$ of travel along the surface and are interpolated to a precise $3.5 \mathrm{~m}$ separation after distance normalization. We recorded with no range gain, and applied none during processing. We postprocessed with high- and low-pass frequency filtering to alleviate noise, and used a two-dimensional Kirchhoff

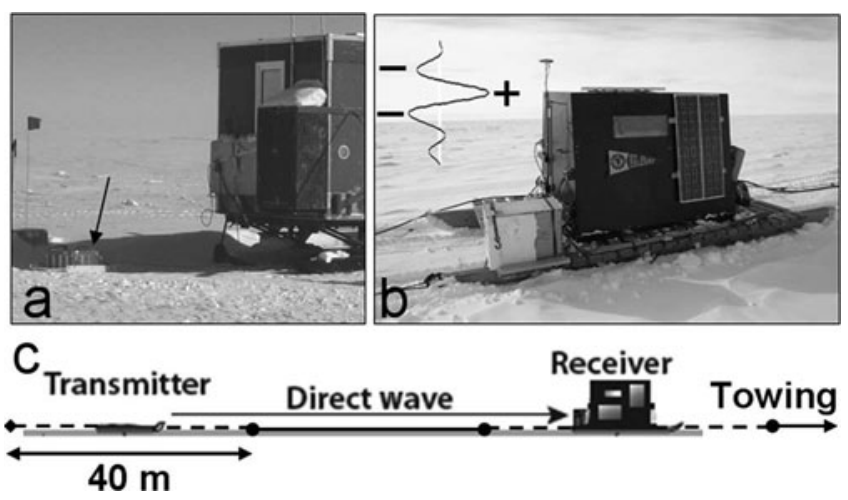

Fig. 2. (a) $200 \mathrm{MHz}$ antenna unit on a Teflon sled; (b) St Olaf $3.2 \mathrm{MHz}$ receiver housing; and (c) diagram of the $3.2 \mathrm{MHz}$ system in tow. In (b), the $3.2 \mathrm{MHz}$ pulse waveform is $80 \mathrm{~m}$ long in ice, which provides $40 \mathrm{~m}$ of vertical interface resolution. The - + symbols indicate the phase polarity sequence of the successive halfcycles. In (c) the dashed lines represent the dipole antennas and the arrow labeled 'Direct wave' depicts the direct coupling by the 3.2 $\mathrm{MHz}$ pulse that masks returns to $135-150 \mathrm{~m}$ depth.

migration to properly place reflection horizons and collapse diffractions.

The direct surface arrival from our free-running transmitter triggered the oscilloscope receiver. In our $3.2 \mathrm{MHz}$ profiles, the top 135-150 m of the firn and ice are masked by the strong direct coupling, which we remove by horizontal filtering to leave only noise to these depths. To compensate for these shallow depths, we simultaneously recorded data in a lower-gain, high-pass filtered (10$20 \mathrm{MHz}$ ) channel that alleviates the direct coupling and allows horizons to be imaged within $42 \mathrm{~m}$ of the surface, as mentioned above. The wide center-to-center $130 \mathrm{~m}$ antenna separation likely provides some, but unknown, distortion of the dip of the shallowest imaged horizons in the range of 42-70 m depth. These higher-frequency profiles are not migrated.

We corrected all profiles for surface elevation. We calibrated depth, $d$, within the profiles using the simple equation

$$
d=c t / \sqrt{\epsilon}
$$

where $c=3 \times 10^{8} \mathrm{~m} \mathrm{~s}^{-1}$ and $\varepsilon=2.7$ for firn and 3.15 for ice. We justify this firn value and the likely error in using it in Part I. The englacial depth calibration employs a normal moveout correction using our antenna separation and the ice value of $\varepsilon$, which for the $10-20 \mathrm{MHz}$ data provides an estimated depth error of $<10 \%$ at the shallowest depth of $42 \mathrm{~m}$. We fixed a $500 \mathrm{~m}$ depth scale grid on all englacial profiles, depicting values relative to the surface elevation at the left-hand edges. At other locations in the profiles, depths relative to the surface may be displaced by up to $50 \mathrm{~m}$ because of changes in the surface elevation across the profile displayed.

We display profiles in a grayscale amplitude format: white indicates positive signal strength, black indicates negative, and gray is near zero. Our englacial 3.2 $\mathrm{MHz}$ and firn-englacial $10-20 \mathrm{MHz}$ profiles are compiled traces of waveform amplitude. Our firn profiles were additionally processed with a Hilbert magnitude transform, which captured pulse amplitude envelopes and increased horizon clarity. Signal amplitude is then represented with dark tones. 


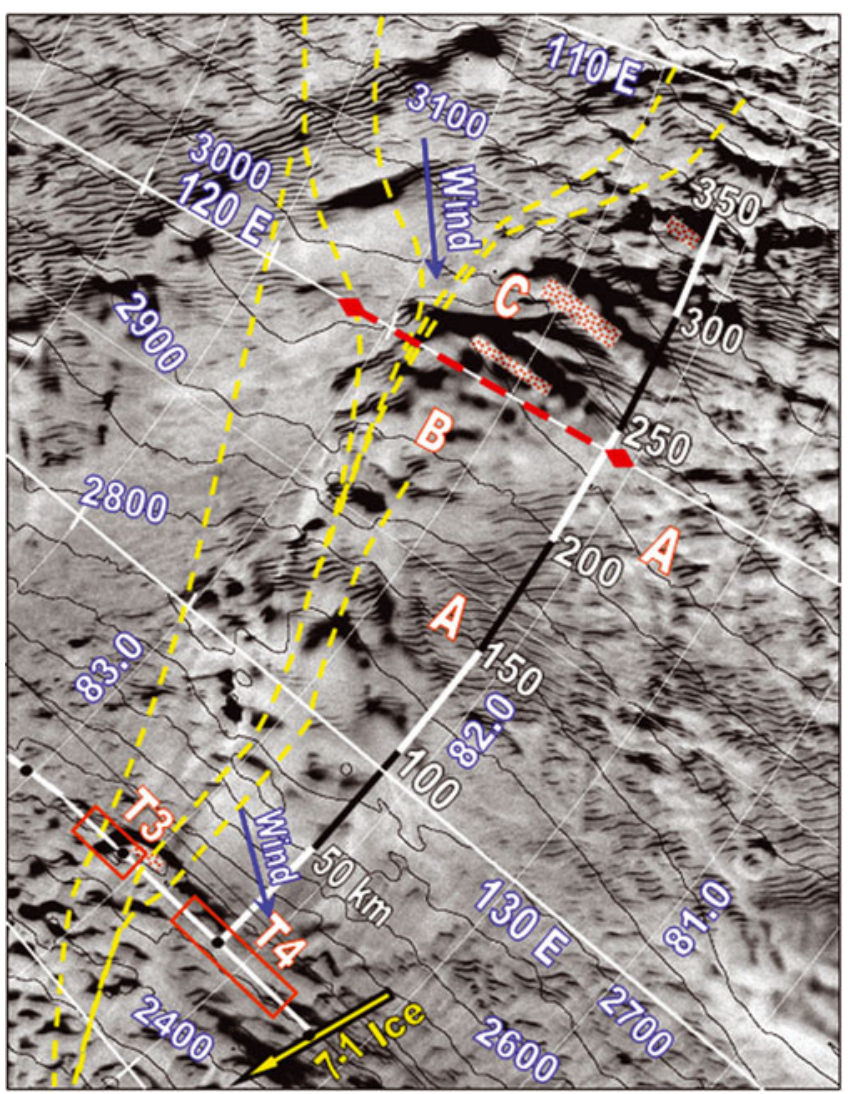

Fig. 3. Segments $\mathrm{T} 3$ and $\mathrm{T} 4$ (red boxes) superimposed on a RADARSAT image that includes the upstream environment. Elevation contours are in meters, and black dots along the traverse are spaced $50 \mathrm{~km}$. We estimate a $\pm 1 \mathrm{~km}$ error in aligning the crossing of the flowlines (yellow dashed) across the traverse. We interpret features near labels A, B and C as the origin of similarly labeled features in Figure 4, as discussed in the text. The red-andwhite dashed line along $120^{\circ} \mathrm{E}$ separates features B and C, the latter of which resides in a region of relatively stronger convergence, as also indicated by folding in the radar profile. The red stippling indicates areas of plateaus identified in $5 \mathrm{~m}$ ICESat (Ice, Cloud and land Elevation Satellite) contours. Elevation contours just west of T4 indicate that ice speed accelerated within this short distance to reach $87 \mathrm{~m} \mathrm{a}^{-1}$ by site $7-1$.

\subsection{GPS}

We used differential kinematic GPS to determine our traverse position and elevation, with an antenna mounted on the traverse vehicle that dragged our $200 \mathrm{MHz}$ radar antenna. Our accuracy for the GPS antenna location is better than $0.2 \mathrm{~m}$ for elevation and better than $0.1 \mathrm{~m}$ for horizontal position, based on root-mean-square values. GPS antenna elevation is corrected for its height above the GPR antennas. The $200 \mathrm{MHz}$ antenna unit was $8.5 \mathrm{~m}$ behind the GPS antenna. The midpoint between the two 3.2 MHz antennas was $\sim 143.5 \mathrm{~m}$ behind the GPS antenna. We correct for the $135 \mathrm{~m}$ displacement between our $200 \mathrm{MHz}$ and lower-frequency profiles, but any misalignment of this order is insignificant given the $30-50 \mathrm{~km}$ scale of our profiles. We measured ice velocity by determining kinematic solutions to 4-20 hours of dual-frequency GPS data each day, with surveys at each site performed at least 1 day apart. Position uncertainty is $8 \mathrm{~mm}$, which corresponds to an error in annually averaged speeds of about $\pm 5.9 \mathrm{~m} \mathrm{a}^{-1}$ and places the error percentage between
$7 \%$ and $20 \%$ over the range of speeds $\left(87-30 \mathrm{~m} \mathrm{a}^{-1}\right.$, respectively) we measured.

\subsection{Satellite imagery}

We show both 2006 MODIS (Moderate Resolution Imaging Spectroradiometer; $620-876 \mathrm{~nm}$ wavelengths, $250 \mathrm{~m}$ resolution) and 1997 RADARSAT- 1 (6 cm wavelength, $125 \mathrm{~m}$ pixel resolution; Liu and others, 2001; Jezek, 2003) satellitebased images to give the surficial context of the environment along and far up-ice of our traverse. Windward slopes generally appear dark in RADARSAT images and light in MODIS images, with the corresponding opposite tonality on leeward slopes. MODIS images best reveal megadunes, while RADARSAT images also show megadunes but best reveal larger and isolated accumulation features in dark tones. The causes of the different tonalities are discussed by Fahnestock and others (2000) and in Part I.

\section{RESULTS: COSETS AND MODIFIED LAYERS}

\subsection{T4: resolved englacial cosets and folding}

Figure 3 shows a RADARSAT image depicting the segment of T4 we discuss and the environment further up the flank of the ice sheet. This segment is $17-67 \mathrm{~km}$ from site $7-1$. The $87 \mathrm{~m} \mathrm{a}^{-1}$ ice speed at site $7-1$ is directed nearly orthogonal to T4. The modeled katabatic wind is $\sim 35^{\circ}$ east of north. The converging ice flowlines of Liu and others (1999) cross at about $10-30 \mathrm{~km}$ further south. Along these flowlines, Bamber and others (2009) indicate anomalous balance speeds in this tributary feeding Byrd Glacier, grading from about $5 \mathrm{ma}^{-1} 250 \mathrm{~km}$ to the west of T4, to $20-30 \mathrm{~m} \mathrm{a}^{-1}$ along T4. These are higher flow speeds than for surrounding areas, but still considerably less than our measured value of $87 \mathrm{ma}^{-1}$ at site $7-1$. The RADARSAT image shows that megadune fields and large dark accumulation features lie farther to the west up the flank of the ice sheet.

Figure 4 shows the $3.2 \mathrm{MHz}$ profile for this segment. Flow is mainly into the page. The englacial stratigraphy is visible from about 150 to $2400 \mathrm{~m}$ depth. The ice-bed horizon contains no special features and is mainly characterized by the simple waveform shown in Figure 2. In general, there are two kinds of englacial horizons in this segment. The first are the major, mainly horizontal (considering the $10 \times$ vertical exaggeration) horizons. They last $<20 \mathrm{~km}$ before merging with another similar major horizon, and occur to nearly $2500 \mathrm{~m}$ depth throughout the record. Many exhibit the same waveform polarity sequence as does the bottom horizon (indicated by small arrows in Fig. 4). The second kind (boxes in Fig. 4) are the bedding horizons, which are unconformable with the major horizons that delineate them. These packages of bedding sequences are cosets, and their reflection horizons are responses to acidic strata. The thicknesses of these cosets are obviously enhanced by the transverse compression evidenced by folding below $\sim 800 \mathrm{~m}$ depth. By analogy with our firn results in Part I, the major horizons are likely responses to a density-modified and recrystallized layer between two sequences. The leading edges, therefore, delineate entire cosets. We discuss their likely relative conductivity below.

Figure 4 shows labels just below several features. Labels A are below layers of speckle, 40-60 m thick. The speckle patterns are likely responses to bedding sequences, the thicknesses of which are insufficient to be well resolved by 


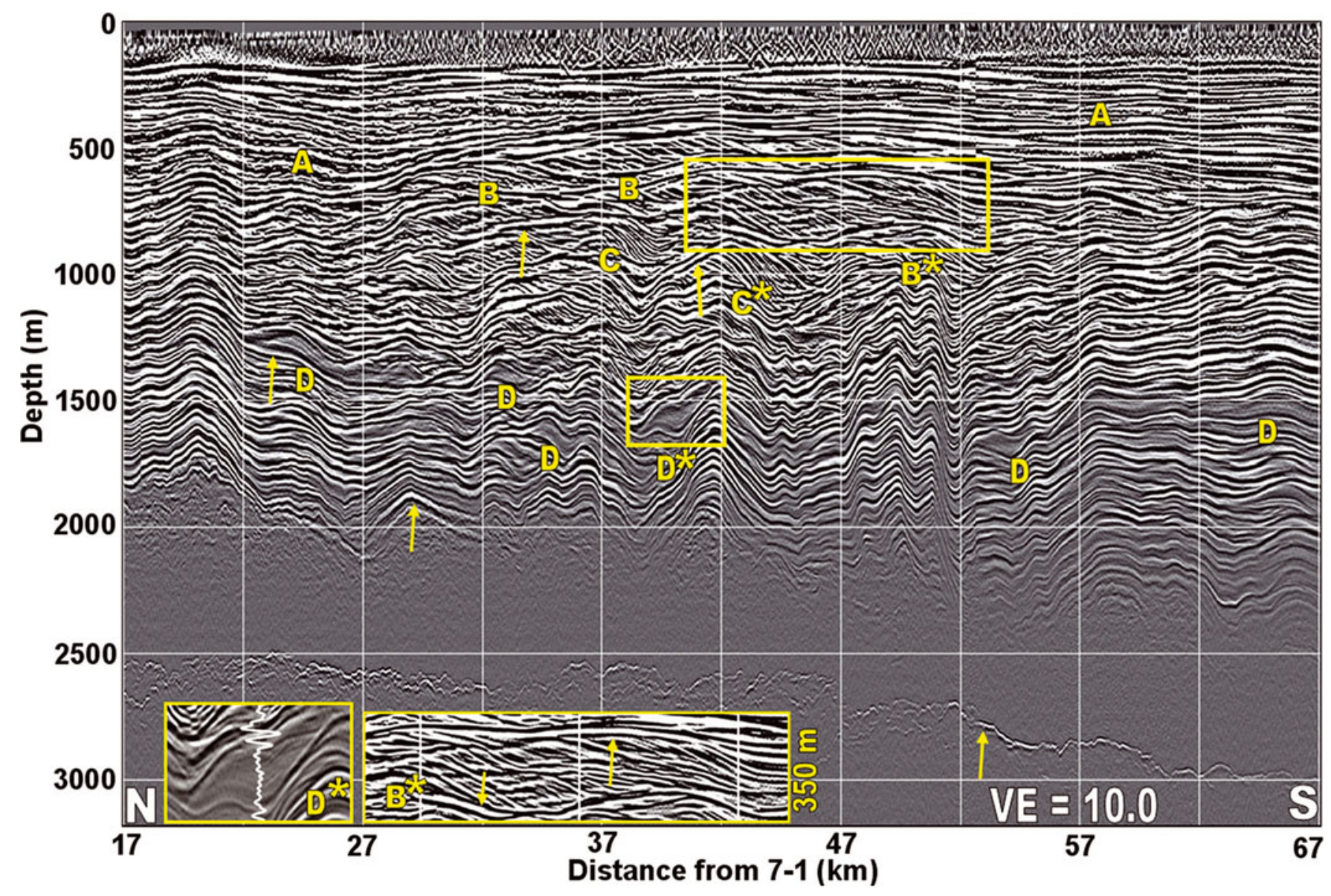

Fig. 4. 3.2 MHz profile of segment T4. Flow is mainly into the page. The depth scale here and in Figure 5 is with respect to the top of the noise band. Label A refers to the speckle features, labels B and C indicate cosets and label D indicates unstratified features. The general folding begins at $\sim 800 \mathrm{~m}$ depth, and separates features B and C. It is often parallel and does not correspond with the subglacial relief. Stratification disappears within $500 \mathrm{~m}$ of the bottom. The detail of B* shows two sigmoidal beds and evidence of an intervening horizon. The unmigrated detail of $\mathrm{D}^{*}$ shows a waveform indicative of a higher conductivity within the unstratified layer. The yellow arrows indicate prominent horizons with the same waveform polarity.

our pulse. These layers occur to $\sim 600 \mathrm{~m}$ depth from 17 to $32 \mathrm{~km}$, decrease to $\sim 400 \mathrm{~m}$ depth from 32 to $52 \mathrm{~km}$ and then deepen to $\sim 600 \mathrm{~m}$ depth on the south side.

Labels B refer to the $5-15 \mathrm{~km}$ long cosets from 400 to $800 \mathrm{~m}$ depth. Their upper delineating horizons dip to the north, while the $2-3 \mathrm{~km}$ long bedding planes dip to the south. Some sigmoidal bedding horizons appear to span $250 \mathrm{~m}$ thickness (Fig. 4, inset), but they are crossed by intermediate and more horizontally disposed horizons, such as those in the inset. Changes in bedding horizon curvature across an intermediate horizon in this inset suggest that this is an image of adjoining sequences from two different cosets, each with a maximum sequence thickness less than $150 \mathrm{~m}$.

Labels $\mathrm{C}$ indicate the thickest cosets and are at 800 $1500 \mathrm{~m}$ depth. They are up to $8 \mathrm{~km}$ long, with most bedding $2-3 \mathrm{~km}$ long that dips south. Their folded, synformal appearance, thickness and starting depth of $\sim 800 \mathrm{~m}$ distinguish cosets $\mathrm{C}$ from cosets $\mathrm{B}$. In the detail in Figure $5 \mathrm{a}$, most of coset $C^{*}$, from 40 to $44 \mathrm{~km}$, shows no consistent evidence for any cross-cutting horizons, and mostly distinct upper and lower delineating horizons, outlined in red. Consequently, $C^{*}$ appears to be a single coset. As a result of folding, the maximum $C^{*}$ sequence thickness of $150 \mathrm{~m}$ in a direction normal to the bedding horizons becomes $210 \mathrm{~m}$ in the vertical direction, including the thickness of the upper delineating horizon. A $150 \mathrm{~m}$ thickness is much greater than the $90 \mathrm{~m}$ we observed for firn cosets in Part I, but is possible because acidic beds, as opposed to density layers, will not extinguish as they deepen into the englacial regime, just as they do in regions of conformable stratigraphy.

The $\mathrm{D}$ features in Figure 4 are $3-8 \mathrm{~km}$ long, occur below $1200 \mathrm{~m}$ depth and reach $160 \mathrm{~m}$ thickness at about $1100 \mathrm{~m}$ above the bed. The similarity of their folded shapes, thicknesses and lengths to those of cosets $C$ suggests they are cosets. However, they contain no internal bedding horizons that do not conform with their delineating horizons. Instead, they contain weak horizons that conform with the horizons above, which means that these internal horizons are multiple reflections generated in an overriding layer. The detail of feature $\mathrm{D}^{*}$ in the Figure 4 inset is unmigrated data, and so precludes any removal of bedding horizons by the migration process. Therefore, these features must have acidic bedding layers that are too thin to resolve; these, along with the waveform in the inset, are discussed below.

Figure 4 reveals that stratigraphic folding begins below $\sim 800 \mathrm{~m}$ depth. Much of the folding appears parallel (Billings, 1972; Suppe, 1985; Roberts, 1989) wherein horizons generally maintain their vertical separation for several kilometers, such as from 47 to $51 \mathrm{~km}$ at 1000-2000 m depth. 


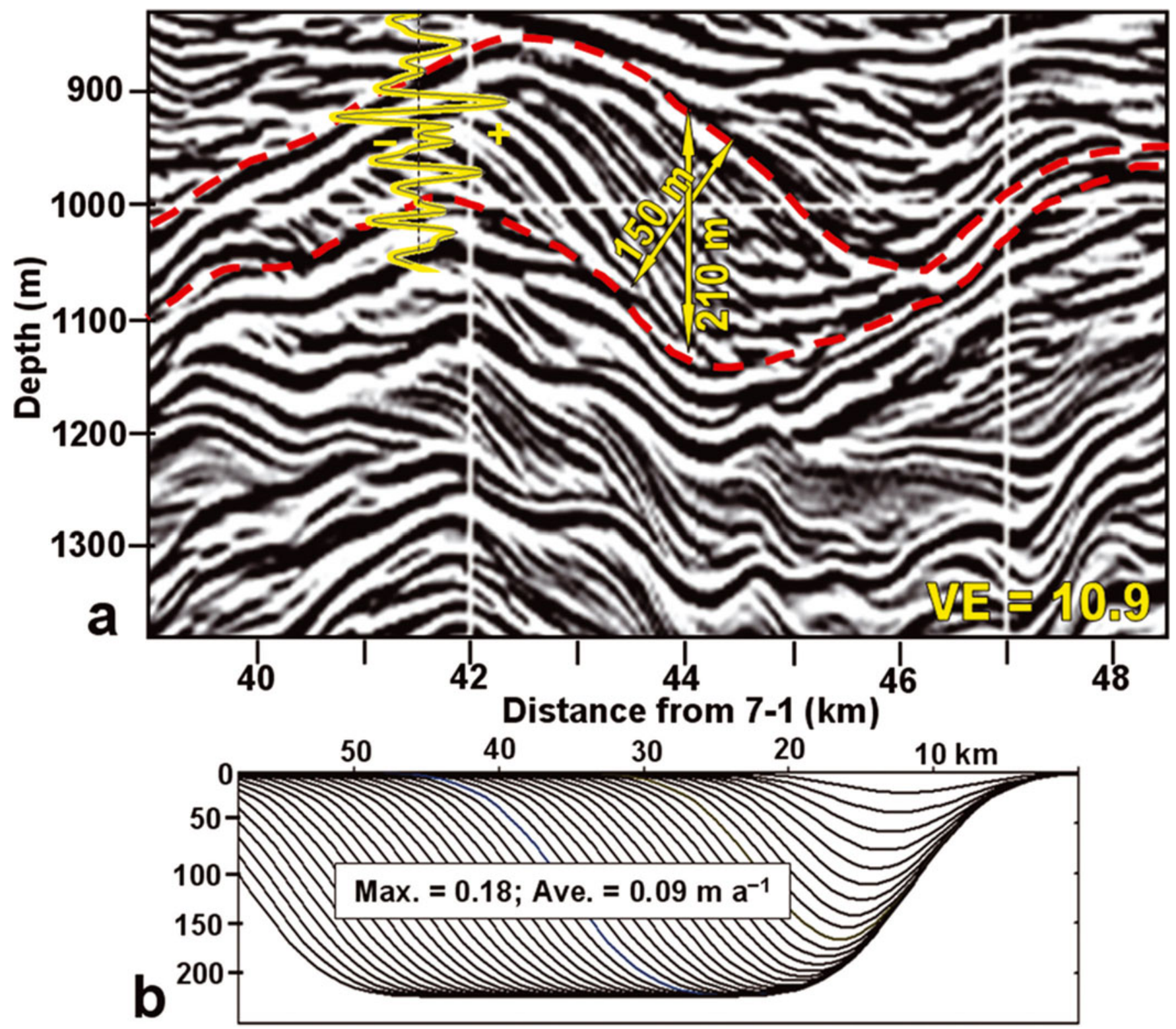

Fig. 5. (a) Coset $C^{*}$ from Figure 4 , and (b) surface model of an axial section without topographic correction, assuming that the radar profile is a transverse section. The dashes in (a) outline our interpreted delineation of this coset, and the polarity sequences of the superposed waveform show that the upper and lower delineating horizons are of relatively higher conductivity. The model in (b) is based on a constant water-equivalent accumulation rate, the maximum and the windward slope average of which are labeled. Each model contour represents 100 years of accumulation.

In addition, folding from 39 to $57 \mathrm{~km}$ is harmonic, whereby the form of the folds generally repeats with depth. In the detail of Figure 5 a the dipping upper and lower delineating horizons of $\mathrm{C}^{*}$ (indicated with dashes) and of two deeper and major horizons are nearly parallel between 42 and $45 \mathrm{~km}$. In other places, nonparallel folding occurs, such as from 51 to $52 \mathrm{~km}$ (Fig. 4) where the dips of some fold limbs steepen and lengthen with depth below $1000 \mathrm{~m}$, and plunge nearly $400 \mathrm{~m}$. The association of this folding with converging flow implies that the folding is transverse to the flow and so the hinge lines are parallel to the flow.

\subsection{T1: unresolved englacial cosets and folding}

The T1 segment spans $71 \mathrm{~km}$ and ends at site 7-2 (Fig. 6). Ice flow is nearly orthogonal to the traverse at site $7-2$, where we measured velocity at $30.09 \mathrm{~m} \mathrm{a}^{-1}$ directed $58^{\circ}$ east of north. Megadunes appear in the RADARSAT image $\sim 80 \mathrm{~km}$ west of the northern end of $\mathrm{T} 1$, and there is an extensive megadune field another $50 \mathrm{~km}$ further west. Several tributary flowlines that converge toward Byrd Glacier (Liu and others, 1999) cross $T 1$ and are consistent with the balance-velocity stream mapped by Bamber and others (2009). Their map shows velocities near site 7-2 similar to our value. The inset in Figure 6 shows the accumulation feature surrounding 7-2. The elevation increases only $33 \mathrm{~m}$ from north to south along this segment, while the ice-bed elevation decreases nearly $1000 \mathrm{~m}$ from -68 to $-49 \mathrm{~km}$, and at least $400 \mathrm{~m}$ from $-15 \mathrm{~km}$ to a location between -6 and $-1 \mathrm{~km}$ (Fig. 7). The latter bed drop lies directly beneath the dark accumulation feature in the inset of Figure 6 (feature a in Part I). Large firn cosets and corresponding subglacial depressions occur for $100 \mathrm{~km}$ south of 7-2 (Part I).

The profile in Figure 7 is across ice flow. All horizons are unconformable because none lasts more than $\sim 30 \mathrm{~km}$ 
before intersecting or apparently merging with another. In contrast with the profile of $\mathrm{T} 4$, all horizons are major because there are no visible bedding sequences. This suggests that the contained bedding sequences are thinner than the $40 \mathrm{~m}$ pulse resolution. This general lack of visible sequences is typical of our profile starting at $110 \mathrm{~km}$ from site 7-1 and continuing for $540 \mathrm{~km}$ south.

The stratigraphy is strongly folded across the entire segment, which includes four of the flowlines of Figure 6. The folding begins at $\sim 200 \mathrm{~m}$ depth. In some places fold limbs are nonparallel because they steepen with depth, such as from 0 to $-3 \mathrm{~km},-6$ to $-8 \mathrm{~km},-22$ to $-23 \mathrm{~km}$, and -50 to $-53 \mathrm{~km}$. However, much folding appears parallel for $2-3 \mathrm{~km}$ along the fold limbs and hinges. Most examples are from -9 to $-21 \mathrm{~km}$ and -26 to $-46 \mathrm{~km}$ below $\sim 1000 \mathrm{~m}$ depth. In the box section of Figure 7, to which we applied extra contrast, nearly parallel folding persists to $>2600 \mathrm{~m}$ depth. The dashed boxes enclose examples of sub-kilometer parallel folding superimposed on the larger folds.

\subsection{T3 and T2: modified layers in the firn-englacial transition}

The englacial profiles of Figures 4 and 5 show major horizons delineating cosets. From Part I it is clear that these horizons are associated with the modified recrystallized layers that first formed in firn. However, it is not clear if the modification affected acidic strata. We address this question next with the comparative profiles in Figures 8 and 9.

Figure 8a depicts segment T3, which is $30 \mathrm{~km}$ long, orthogonal to ice flow and $\sim 35^{\circ}$ to the modeled wind direction. From 105 to $110 \mathrm{~km} \mathrm{T3}$ crosses the large accumulation feature seen in the RADARSAT image and situated over a large ice-bed depression with at least $450 \mathrm{~m}$ of relief (Fig. 8d). T3 also crosses merging flowlines 80-120 km from site 7-1 (Fig. 3). Consistently, the 200 and $10-20 \mathrm{MHz}$ profiles (Fig. 8b and c) show a large asymmetric synform with a fold axis that dips from about 2.4 to $3.1^{\circ}$ to the north. Figure $8 \mathrm{c}$ shows that the synformal strata are underlain by an unconformable horizon (arrow), which we interpret as the lower delineating layer of this bedding sequence. Consequently this is a coset in transverse sectional view, with windward slope up-ice and likely situated over a large ice-bed depression.

Figure $8 \mathrm{~b}$ shows that at $200 \mathrm{MHz}$ the southerly dipping firn-density beds on the northern flank cover $\sim 15 \mathrm{~km}$ and reach at least $90 \mathrm{~m}$ depth. At $10-20 \mathrm{MHz}$ in Figure $8 \mathrm{c}$ these beds appear as acidic-based horizons that end at the unconformable, stronger reflecting acidic-based horizon that continues to the southern flank where it rises and becomes conformable with the density-based horizons. By $114 \mathrm{~km}$ the $200 \mathrm{MHz}$ dipping beds on the southern flank contain several modified and recrystallized layers that become nearly horizontal below $42 \mathrm{~m}$ depth. By $60 \mathrm{~m}$ depth, there is no evidence of density stratification. In contrast, the $10-20 \mathrm{MHz}$ horizons that occur within the same depth section are generally parallel to the $200 \mathrm{MHz}$ unstratified layers, and so reveal that acid-based strata remain within modified and recrystallized firn.

Segment T2 is $185-220 \mathrm{~km}$ south of site $7-1$ (Fig. 9a and b). The modeled wind direction is $\sim 40^{\circ}$ off the traverse direction. Based on topographic contours, ice flow is $60^{\circ}$ east of north, but could be as much as $77^{\circ}$ based on an interpolation between the measured values at sites 7-1 and

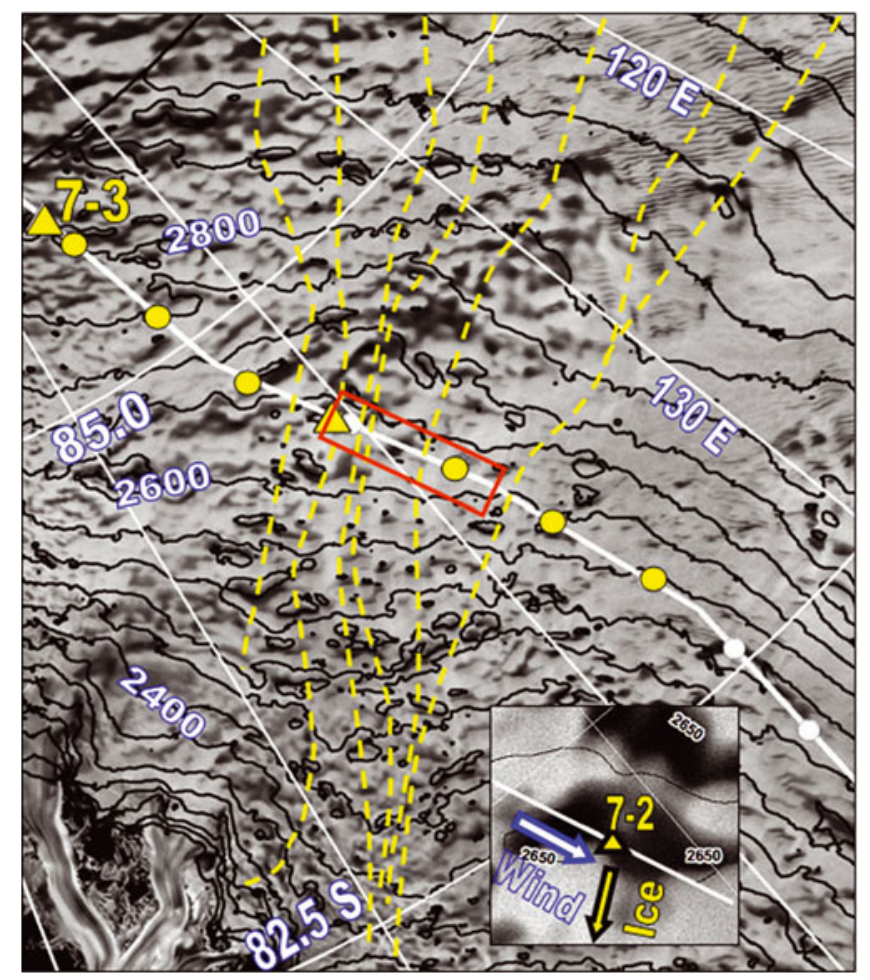

Fig. 6. Segment T1 (red box) and dashed ice flowlines superimposed on the 1997 RADARSAT image. Elevation contours are in $50 \mathrm{~m}$ increments, and yellow dots are $50 \mathrm{~km}$ apart. Dune fields appear $\sim 130 \mathrm{~km}$ to the west. Katabatic wind direction is nearly parallel to T1. The inset shows the accumulation environment of site $7-2$; the white diagonal line is $30 \mathrm{~km}$ long.

7-2. In either case, ice flow is strongly oblique to T2. Megadune-type features within MODIS and RADARSAT images (Fig. 9a and b) appear $\sim 10 \mathrm{~km}$ to the west, where their strikes are generally orthogonal to the modeled wind direction. Consequently, the radar profiles of Figure 9c and d are mainly transverse sections of cosets, so most horizons would be expected to appear generally horizontal.

The $200 \mathrm{MHz}$ firn profile in Figure 9c is dominated by the recrystallized layers, which have grown and thereby merged to appear continuous across the entire profile, and large unstratified recrystallized zones from 42 to $90 \mathrm{~m}$ depth (the implications of the continuity are discussed in the appendix to Part I). In contrast, within the corresponding depth range, the $10-20 \mathrm{MHz}$ profile of Figure $9 \mathrm{~d}$ shows many acidic horizons that generally track with the recrystallized layers in Figure 9c, especially between 192 and $211 \mathrm{~km}$. Similar tracking holds for all $10-20 \mathrm{MHz}$ horizons south of site 7-1. Although acidic horizons are weak within depth sections from 185 to $193 \mathrm{~km}$ and from 211 to $220 \mathrm{~km}$, they still conform to nearby upper or lower horizons. The cross bedding in the $10-20 \mathrm{MHz}$ profile near $187 \mathrm{~km}$ (arrow) is evidence that the upper and lower horizons confine a bedding sequence.

\section{DISCUSSION}

\subsection{Modified layers}

In firn, our comparisons between the two radar profiles within both Figures 8 and 9 show that acidic stratification is 


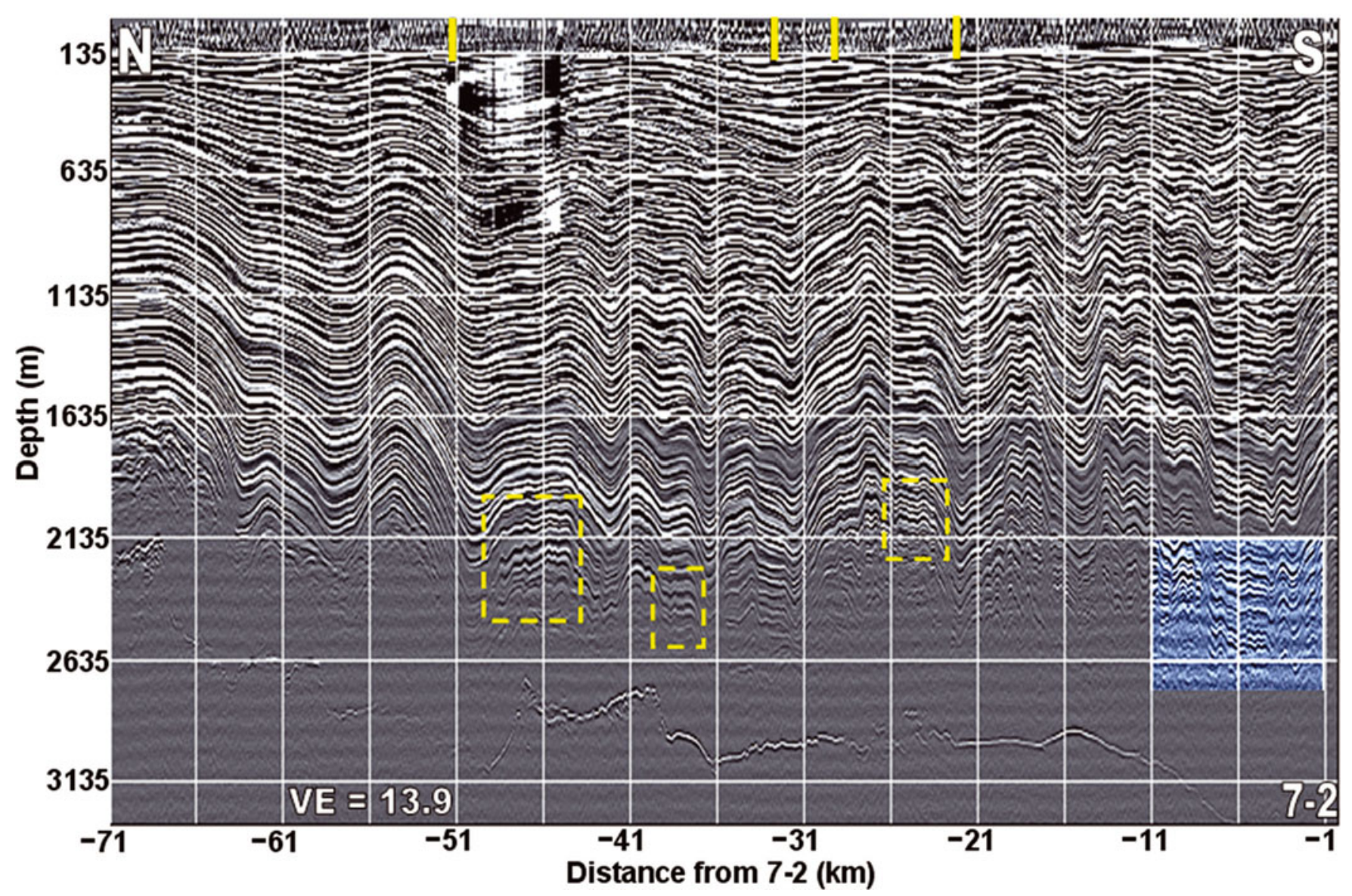

Fig. 7. 3.2 MHz englacial profile of the transverse folded section of T1. The depth scales are with respect to the top of the noise band. Flow is into the page. The yellow vertical lines locate flowline crossings in Figure 6. The dashed boxes enclose fine-scale folds superimposed on large-scale folds. The increased contrast in the box at lower right reveals the depth of the parallel folding.

retained where recrystallization has removed density stratification. Consequently, after recrystallization, which is promoted by vapor transport after burial, an acidic signature of the original isochronal unconformity is retained. It is likely that some acidic modification has occurred because post-depositional decreases in concentration of chemical species in very near-surface firn have been attributed to reemission into the atmosphere and to diffusion (Proposito and others, 2002). In deep firn, recrystallization that accompanies compression obviously does not suppress conductivity in general, as evidenced by any englacial icesheet radar profile.

Englacially, the retention of acidic stratification is consistent with our interpretation of modified firn layers being the cause of major horizons. In Figure 4 many of the unconformable horizons have the same black-white-black (-+- ) half-cycle polarity sequence as the bottom horizon, by which we mean the same waveform polarity sequence seen in Figure 2. Examples of this horizon waveform are in the $\mathrm{D}^{*}$ inset of Figure 4 and in the $\mathrm{C}^{*}$ detail of Figure $5 \mathrm{a}$. This polarity sequence indicates a reflection either from an interface between a relatively low- $\sigma$ layer and one of higher $\sigma$ below, or, as must occur above and below the $\mathrm{C}^{*}$ sequence, of an embedded thin (much less than the $40 \mathrm{~m}$ long pulse resolution) layer with higher $\sigma$ than that of the ice matrix (Arcone and others, 2004). Despite the lack of visible stratification within the D* feature of Figure 4, the waveform of the horizon above it suggests that an embedded high- $\sigma$ layer is the case for this feature as well.

The major, delineating horizons of cosets B, C and D in Figures 4 and $5 a$ appear nearly continuous either because the sigmoidal acidic beds that make up these horizons have sufficiently turned over to preclude the ability of the $3.2 \mathrm{MHz}$ pulse to resolve their change in slope, or because they are too close to be resolved, or both. In Figure 5a, the beds appear unconformable with the upper delineating horizon from 40 to $43 \mathrm{~km}$, but nearly conformable with it from 43 to $45 \mathrm{~km}$ where their slope is closer to that of the delineating horizon. The inset of feature $\mathrm{B}^{*}$ in Figure 4 shows an example where the inflection associated with the change in curvature between adjoining beds is resolved. The obvious acidic nature of the upper delineating horizons for features $D$ indicates that the sigmoidal continuations of these acidic beds have likely thinned sufficiently from strain to preclude their resolution.

\subsection{Parallel folding, and origin of $\mathrm{T} 4$ cosets}

Segments T1 and T4 are the only segments along the entire traverse with this degree of folding. Parallel folding indicates constant vertical strain because layers maintain their thicknesses throughout the fold. Consequently, slip occurs along bedding planes, and in Figures 4 and 7 it appears to reach to within a few hundred meters of the bottom. In nonparallel folding, the steepening and lengthening of fold limbs with depth indicates increasing vertical strain with age 
(Ng and Conway, 2004). Both are present here, so the overall pattern suggests a history of stick-slip behavior. The deep harmonic and parallel folding in Figure 4 led us to assume the possibility that this transverse compression may have occurred throughout the ice-sheet thickness (as in Fig. 7) when it happened up-ice-flow, and that up-ice basal slip in the axial along-flow direction has historically permitted any large windward-slope accumulation features to stabilize over large subglacial depressions (Budd and Carter, 1971; Part I). Basal slip below deeply frozen and slow-moving ice has been documented (Echelmeyer and Wang, 1987; Cuffey and others, 1999).

These flowlines, speeds, evidence of up-ice basal slip and evidence in Part I for topographic stability of large accumulation slopes lead us to identify the large cosets in Figure 4 with the similarly labeled features $\mathrm{A}-\mathrm{C}$ in Figure 3. The northern offset of these features from the flowlines projects their associated strata to cross T4. Cosets generated within megadune fields likely have thicknesses less than the $40 \mathrm{~m}$ resolution of our pulse. Consequently, we interpret the speckle features, A, across the top of the entire profile in Figure 4, as having originated before and within the megadune fields labeled $A$ in Figure 3 . These features begin about $100-125 \mathrm{~km}$ from T4 and are up to $600 \mathrm{~m}$ deep within the first $32 \mathrm{~km}$ from site $7-1$. We identify features $B$ and $C$ in Figure 3 as the sources for cosets $B$ and $C$ in Figure 4. Cosets $B$ are at about $400-800 \mathrm{~m}$ depth. Cosets C are at about 800-1500 m depth and within the folded regime, which suggests that they originated in the convergence zone that ends by $\sim 240 \mathrm{~km}$ west of $\mathrm{T} 4$ at $120^{\circ} \mathrm{E}$ in Figure 3 . The red stippling in Figure 3 indicates plateaus we identified in $5 \mathrm{~m}$ (elevation) ICESat (Ice, Cloud and land Elevation Satellite) contours, and that lie just up-flow and generally downwind of some of the dark accumulation zones.

Assuming uniform vertical strain, an $800 \mathrm{~m}$ depth over ice $2600 \mathrm{~m}$ thick and an average accumulation rate of $0.05 \mathrm{~m}$ w.e. $\mathrm{a}^{-1}$ represents $\sim 19120$ years. At a distance of $240 \mathrm{~km}$ from T4, this time translates to an average ice balance speed of $12.55 \mathrm{~m} \mathrm{a}^{-1}$. As seen in Figure 3, from 240 to $50 \mathrm{~km}$ going east toward T4 the elevation decreases from about $2970 \mathrm{~m}$ to $2650 \mathrm{~m}$, for a total drop of $\sim 320 \mathrm{~m}$. Then, over the last $50 \mathrm{~km}$ the elevation drops $\sim 190 \mathrm{~m}$. This greater than $2 \times$ increase of surface slope means the ice speed greatly increased over the last $50 \mathrm{~km}$ to T4. Assuming an average speed of $5 \mathrm{~m} \mathrm{a}^{-1}$ from 240 to $50 \mathrm{~km}$ and an average of $41 \mathrm{~m} \mathrm{a}^{-1}$ after $50 \mathrm{~km}$ to bring the speed along T4 up to $87 \mathrm{~m} \mathrm{a}^{-1}$ at site $7-1$ only $50 \mathrm{~km}$ to the south, the average for the $240 \mathrm{~km}$ distance is $12.50 \mathrm{~m} \mathrm{a}^{-1}$. This speed distribution gives an average of $19.4 \mathrm{~m} \mathrm{a}^{-1}$ over the $125 \mathrm{~km}$ distance to megadune fields, and places the first appearance of the megadune fields cosets at $300 \mathrm{~m}$ depth.

The up-ice flow and wind directions and the strikes of RADARSAT features $B$ and $C$ in Figure 3 suggest that cosets B and $C$ in Figures 4 and 5 a must be depicted in transverse section, similar to the asymmetric synformal section of the coset in T3 (Fig. 8). Further evidence that they are in transverse view comes from their bed and sequence lengths. From north to south, GPR cosets B are $8-15 \mathrm{~km}$ long with bed lengths $<2.5 \mathrm{~km}$, and cosets $C$ are $<10 \mathrm{~km}$ long and with beds $<2.5 \mathrm{~km}$ long. These bed lengths are much shorter than those we profiled for the thick firn cosets in figure 2 of Part I or than those we deduced in Part I to be as long as the windward slopes. Consistently, from 100 to $350 \mathrm{~km}$ in Figure 3 , accumulation features $B$ are about $5-8 \mathrm{~km}$ wide

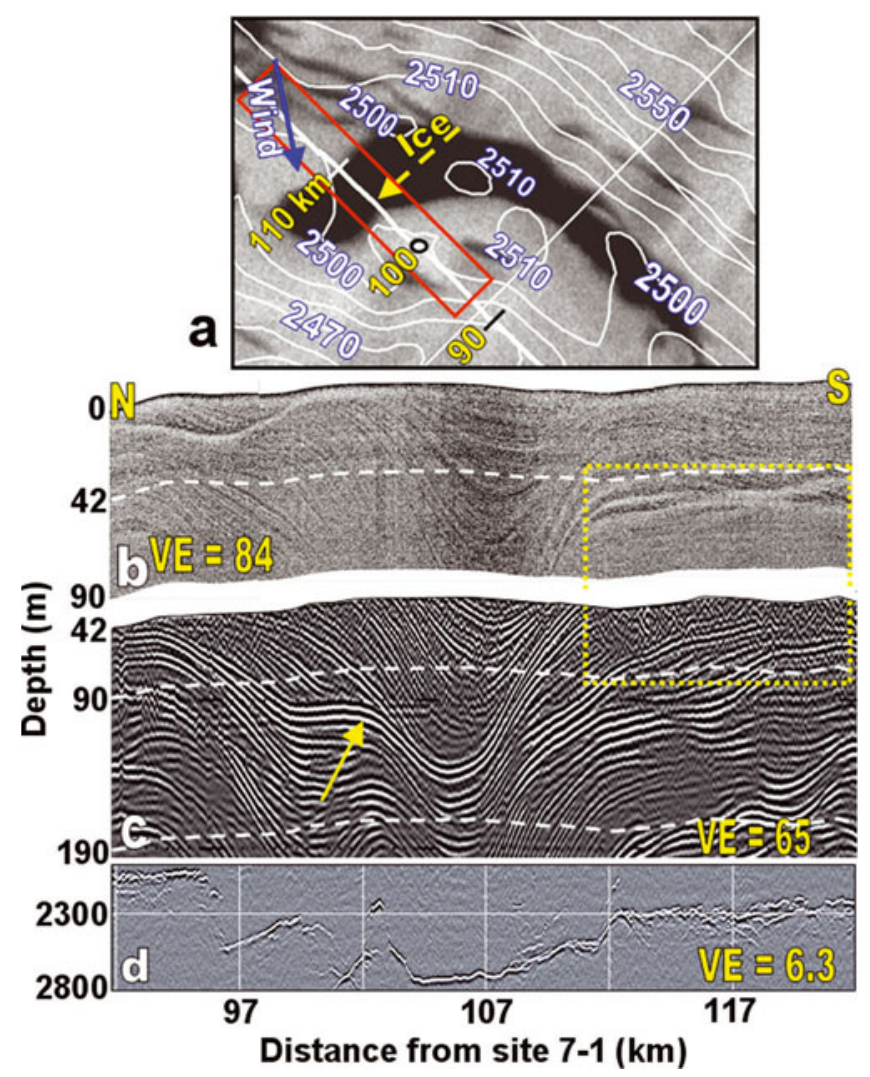

Fig. 8. (a) Segment T3 (red box) superimposed on a RADARSAT image, (b) $200 \mathrm{MHz}$ profile, (c) $10-20 \mathrm{MHz}$ profile of the firnenglacial transition, and (d) bottom topographic profile. The ice direction arrow in (a) is $10 \mathrm{~km}$ long. The arrow in (c) indicates the horizon we interpret as defining the bottom of this large, transversely synformal coset. The portion of the dotted box in (b) contains modified strata within which acidic-based horizons are revealed in (c).

from east to west and up to $20 \mathrm{~km}$ long from north to south, and features $C$ are $8-12 \mathrm{~km}$ wide and up to $75 \mathrm{~km}$ long from north to south. Consequently, their bed lengths, if projected along ice flow, would likely compare well with the RADARSAT east-to-west feature dimensions and be much longer than they appear in Figure 4.

We use our modeling approach of Part I to estimate an accumulation rate for coset $C^{*}$. This approach assumes that accumulation rate is sufficient to maintain a windward slope over a fixed ice-bed depression. At its minimal depth of $850 \mathrm{~m}$, and at $1750 \mathrm{~m}$ above the bed, the Nye model (Nye, 1957; see also Dansgaard and Johnsen, 1969) for constant vertical strain translates $150 \mathrm{~m}$ thickness to a precompression ice thickness of $223 \mathrm{~m}$ near the surface at $2600 \mathrm{~m}$ above the bed. Given that the profile of Figure $5 \mathrm{a}$ is a synformal section transverse to the axial plane, we then form an axial plane model in Figure $5 b$, with a bed length of $10 \mathrm{~km}$, as per the across-strike width of features $C$ in Figure 3. For an ice speed $v=5 \mathrm{~m} \mathrm{a}^{-1}$ and $10 \mathrm{~km}$ bed length (exponential factor $D=0.1$ in Part I), peak and average (along the slope) accumulation rates of 0.18 and $0.09 \mathrm{~m}$ w.e. $\mathrm{a}^{-1}$, respectively, achieve $223 \mathrm{~m}$ thickness. As we found in Part I, these rates are significantly above estimated regional averages, which led us to conclude that they would only partially compensate for the widespread glaze of these regions if estimated regional accumulation rates of $0.04-0.05 \mathrm{~m} \mathrm{a}^{-1}$ are to be realized. 

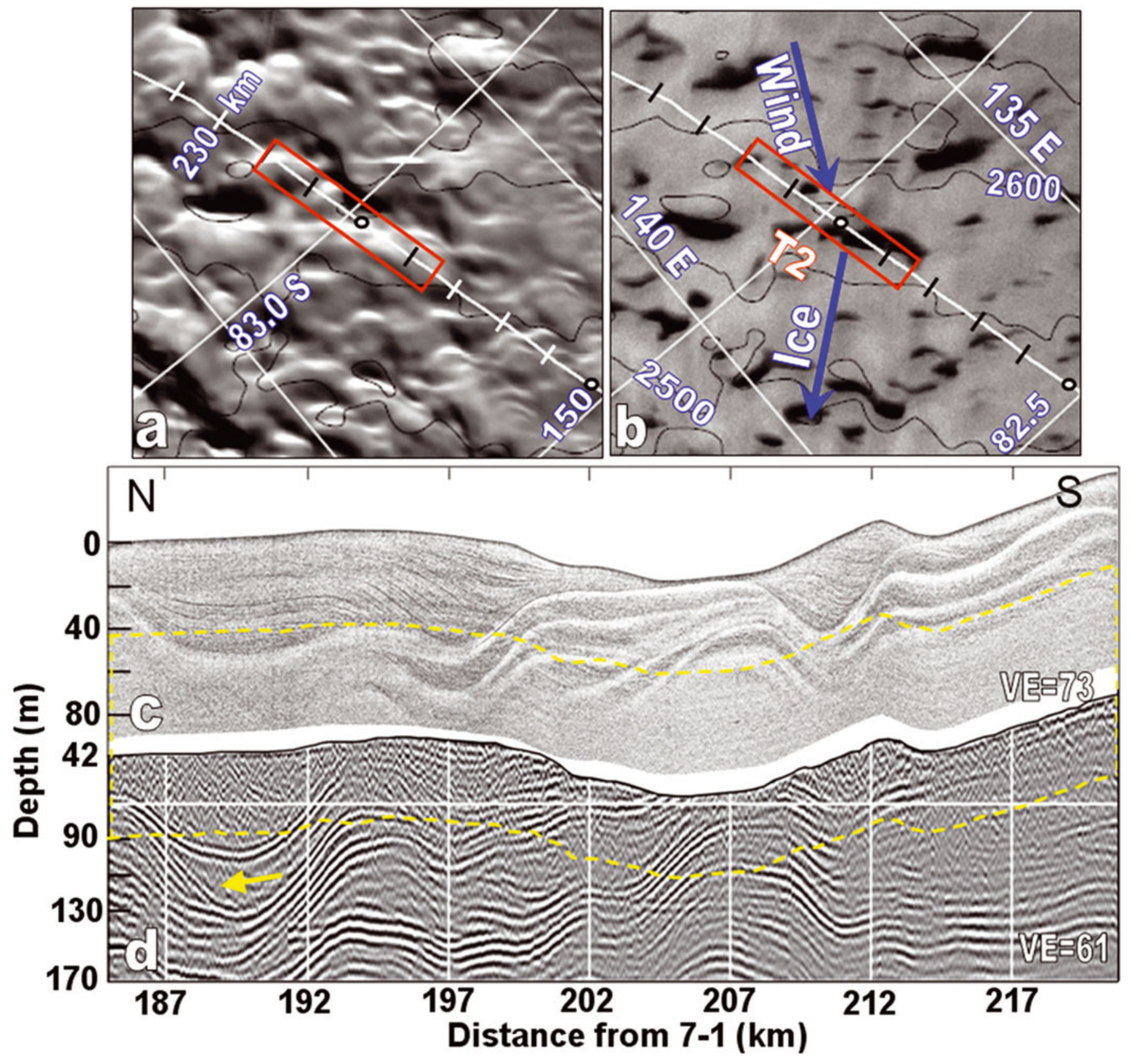

Fig. 9. (a) MODIS and (b) RADARSAT images of the environment of segment T2 (red box), and (c) $200 \mathrm{MHz}$ firn profile and (d) 10-20 MHz profile of the firn-englacial transition. Distances along the traverse in (a) and (b) are measured from site 7-1, and elevation contours are in $50 \mathrm{~m}$ increments. Irregular megadune-type features west of T2 are best seen in (a), while isolated accumulation features are best seen in (b). The strikes of the dunes are nearly normal to the modeled wind. In (c) and (d) ice flow is mainly into the page. The dashed box encloses the same depths within which there is loss of density strata in (c) but acidic strata remain in (d). The arrow in (d) indicates a bedding sequence confined by upper and lower modified layers.

\section{CONCLUSIONS}

Within the limitations of our $40 \mathrm{~m}$ pulse resolution, deeply buried cosets of bedding sequences are not common along our entire $650 \mathrm{~km}$ long profile. Where they occur they indiate large accumulation features farther up the flank of the ice sheet, similar to what we present in Part I for firn cosets. Acidic stratification within formerly modified firn layers produces the major unconformable horizons that delineate these cosets. Consequently, any post-burial recrystallized growth (Part I) may not affect the true isochronal unconformable surfaces of the original glazed accumulation hiatus, as defined by any acidic horizon. We were fortunate that our $3.2 \mathrm{MHz}$ radar was able to resolve so many of these cosets and unconformable horizons. Future englacial GPR profiling would greatly benefit from a shorter pulse to better resolve coset bedding, the structure within the unconformable delineating horizons, and the parallel nature of the folds. A $20 \mathrm{MHz}$ transient system would provide $6 \mathrm{~m}$ of vertical resolution, and even $150 \mathrm{MHz}$ systems (Gogineni and others, 2001) have profiled englacial layering and the ice bed under deep ice.

We interpret the parallel aspect of the folding to indicate possible basal slip or stick-slip behavior at the time of coset formation. Basal slip implies surface topographic stability over large subglacial depressions, intensified accumulation, and that our large and ancient englacial cosets were 
generated beneath present accumulation features farther west at higher elevation. Velocity, accumulation and radar measurements along ice flow and over features B and C of Figure 3 would help verify this interpretation, and the presence of transverse folding in that area.

Unconformable strata must exist throughout and proximal to the Byrd catchment dune fields because the orientation and $650 \mathrm{~km}$ length of our traverse provide a large sample of up-ice englacial and firn strata. Similar englacial strata obviously exist down-ice of the traverse. The $>2000 \mathrm{~m}$ depth that we profiled shows that the uneven processes of intensified accumulation on windward slopes and wind-glaze on leeward slopes, both within megadune fields and in their peripheral areas, have existed in this region for tens of thousands of years.

\section{ACKNOWLEDGEMENTS}

This research was supported by US National Science Foundation (NSF) Office of Polar Programs (OPP) grants 188643 (Arcone), 188987 (Jacobel) and 188765 (Hamilton). We thank Brian Welch for acquiring the $3.2 \mathrm{MHz}$ radar data, and students at St Olaf College for assistance in the processing; Daniel Breton for recording and processing GPS data; Brian Tracey, Seth Campbell, Kristin Schild and Monica Palmer for satellite image processing; Ted Scambos for comments and suggestions; two anonymous reviewers; and Paul Mayewski for his organization and leadership of the ITASE projects. Permission to publish was granted by Director, Cold Regions Research and Engineering Laboratory.

\section{REFERENCES}

Arcone SA and Kreutz K (2009) GPR reflection profiles of Clark and Commonwealth Glaciers, Dry Valleys, Antarctica. Ann. Glaciol., 50(51), 121-129 (doi: 10.3189/172756409789097531)

Arcone SA, Spikes VB, Hamilton GS and Mayewski PA (2004) Stratigraphic continuity in $400 \mathrm{MHz}$ short-pulse radar profiles of firn in West Antarctica. Ann. Glaciol., 39, 195-200 (doi: 10.3189/172756404781813925)

Arcone SA, Spikes VB and Hamilton GS (2005a) Phase structure of radar stratigraphic horizons within Antarctic firn. Ann. Glaciol., 41, 10-16 (doi: 10.3189/172756405781813267)

Arcone SA, Spikes VB and Hamilton GS (2005b) Stratigraphic variation in polar firn caused by differential accumulation and ice flow: interpretation of a $400 \mathrm{MHz}$ short-pulse radar profile from West Antarctica. J. Glaciol., 51(174), 407-422 (doi: 10.3189/172756505781829151)

Arcone SA, Jacobel R and Hamilton G (2012) Unconformable stratigraphy in East Antarctica: Part I. Large firn cosets, recrystallized growth, and model evidence for intensified accumulation. J. Glaciol., 58(208), 240-252

Bamber JL, Gomez-Dans JL and Griggs JA (2009) A new $1 \mathrm{~km}$ digital elevation model of the Antarctic derived from combined satellite radar and laser data - Part 1: data and methods. Cryosphere, 3(1), 101-111

Billings MP (1972) Structural geology. Prentice Hall, Englewood Cliffs, NJ

Budd WF and Carter DB (1971) An analysis of the relation between the surface and bedrock profiles of ice caps. J. Glaciol., 10(59), 197-209

Cuffey KM, Conway H, Hallet B, Gades AM and Raymond CF (1999) Interfacial water in polar glaciers and glacier sliding at $-17^{\circ} \mathrm{C}$. Geophys. Res. Lett., 26(6), 751-754
Dansgaard W and Johnsen SJ (1969) A flow model and a time scale for the ice core from Camp Century, Greenland. J. Glaciol., 8(53), 215-223

Echelmeyer K and Wang Z (1987) Direct observation of basal sliding and deformation of basal drift at sub-freezing temperatures. J. Glaciol., 33(113), 83-98

Fahnestock MA, Scambos TA, Shuman CA, Arthern RJ, Winebrenner DP and Kwok R (2000) Snow megadune fields on the East Antarctic Plateau: extreme atmosphere-ice interaction. Geophys. Res. Lett., 27(22), 3719-3722 (doi: 10.1029/1999GL011248)

Fahnestock MA, Shuman CA, Albert M and Scambos T (2004) Satellite, observational, meteorological and thermal records from two sites in the Antarctic megadunes - stability of atmospheric forcing, thermal cracking, and the seasonal evolution of the thermal profile. Eos, 85(47), F455 [Abstr. C31C-03]

Frezzotti M, Gandolfi S and Urbini S (2002) Snow megadunes in Antarctica: sedimentary structure and genesis. J. Geophys. Res., 107(D18), 4344 (doi: 10.1029/2001JD000673)

Gogineni S and 9 others (2001) Coherent radar ice thickness measurements over the Greenland ice sheet. J. Geophys. Res., 106(D24), 33 761-33 772

Hempel L, Thyssen F, Gundestrup N, Clausen HB and Miller H (2000) A comparison of radio-echo sounding data and electrical conductivity of the GRIP ice core. J. Glaciol., 46(154), 369-374 (doi: 10.3189/172756500781833070)

Jacobel RW and 6 others (2008) Accumulation patterns and basal conditions from radar observations along the US-ITASE traverse in East Antarctica. Eos, 89(53), Fall Meet. Suppl. [Abstr. C31B-0486]

Jacobel RW, Lapo KE, Stamp JR, Youngblood BW, Welch BC and Bamber JL (2010) A comparison of basal reflectivity and ice velocity in East Antarctica. Cryosphere, 4(4), 447-452 (doi: 10.5194/tc-4-447-2010)

Jezek KC (2003) Observing the Antarctic ice sheet using the RADARSAT-1 synthetic aperture radar. Polar Geogr., 27(3), 197-209 (doi: 10.1080/789610167)

Liu H, Jezek KC and Li B (1999) Development of an Antarctic digital elevation model by integrating cartographic and remotely sensed data: a geographic information system based approach. J. Geophys. Res., 104(B10), 23 199-23 213 (doi: 10.1029/ 1999JB900224)

Liu H, Jezek K, Li B and Zhao Z (2001) Radarsat Antarctic mapping project digital elevation model version 2. National Snow and Ice Data Center, Boulder, CO. Digital media: http://nsidc.org/data/ nsidc-0082.html

Mayewski PA (2003) Antarctic oversnow traverse-based Southern Hemisphere climate reconstruction. EOS, 84(22), 205-210

Moore JC, Wolff EW, Clausen HB and Hammer CU (1992) The chemical basis for the electrical stratigraphy of ice. J. Geophys. Res., 97(B2), 1887-1896

$\mathrm{Ng} \mathrm{F}$ and Conway H (2004) Fast-flow signature in the stagnated Kamb Ice Stream, West Antarctica. Geology, 32(6), 481-484

Nye JF (1957) The distribution of stress and velocity in glaciers and ice-sheets. Proc. R. Soc. London, Ser. A, 239(1216), 113-133

Parish TR (1988) Surface winds over the Antarctic continent: a review. Rev. Geophys., 26(1), 169-180

Parish TR and Bromwich DH (1987) The surface windfield over the Antarctic ice sheets. Nature, 328(6125), 51-54

Proposito $M$ and 9 others (2002) Chemical and isotopic snow variability along the 1998 ITASE traverse from Terra Nova Bay to Dome C, East Antarctica. Ann. Glaciol., 35, 187-194 (doi: 10.3189/172756402781817167)

Roberts JL (1989) The Macmillan field guide to geological structures. Macmillan, London

Scambos T, Fahnestock M, Shuman C and Bauer R (2004) Antarctic megadunes: characteristics and formation. EOs, 85(47), F455 [Abstr. C31C-04]

Severinghaus JP and 12 others (2010) Deep air convection in the firn at a zero-accumulation site, central Antarctica. Earth Planet. Sci. Lett., 293(3-4), 359-367 (doi: 10.1016/ j.epsl.2010.03.003) 
Shabtaie S and Bentley CR (1995) Electrical resistivity sounding of the East Antarctic ice sheet. J. Geophys. Res., 100(B2), 1933-1954

Siegert MJ, Hindmarsh RCA and Hamilton GS (2003) Evidence for a large surface ablation zone in central East Antarctica during the last Ice Age. Quat. Res., 59(1), 114-121 (doi: 10.1016/S00335894(02)00014-5)

Stearns LA (2007) Outlet glacier dynamics in East Greenland and East Antarctica. (PhD thesis, University of Maine)

Suppe J (1985) Principles of structural geology, Prentice Hall, Englewood Cliffs, NJ
Welch BC and Jacobel RW (2003) Analysis of deep-penetrating radar surveys of West Antarctica. Geophys. Res. Lett., 30(8), 1444 (doi: 10.1029/2003GL017210)

Welch BC and Jacobel RW (2005) Bedrock topography and wind erosion sites in East Antarctica: observations from the 2002 US-ITASE traverse. Ann. Glaciol., 41, 92-96 (doi: 10.3189/ 172756405781813258)

Welch BC, Jacobel RW and Arcone SA (2009) First results from radar profiles collected along the US-ITASE traverse from Taylor Dome to South Pole (2006-2008). Ann. Glaciol., 50(51), 35-41 (doi: 10.3189/172756409789097496)

MS received 8 March 2011 and accepted in revised form 20 December 2011 